Dr. Samia Kara

\title{
The graphic organiser as a reading strategy: A semantic differential measurement of MA researchers' attitudes
}

\author{
Dr Samia Kara, \\ Department of English and Scientific Methods, GUC, Egypt
}

ملخص: تعرض هذه الورقة تقريز ا عن تقييم للمنظم البياني باعتباره استر اتيجية للقز اءة

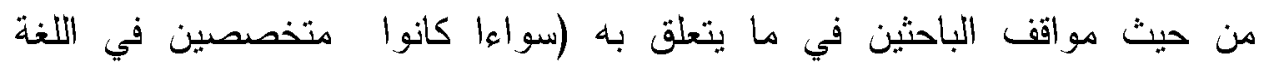
الانجليزية أو يستخدمونها كلغة أبحاثه). و قد هن أثثر تساؤلا بشأن خبرتهم مع المنظم

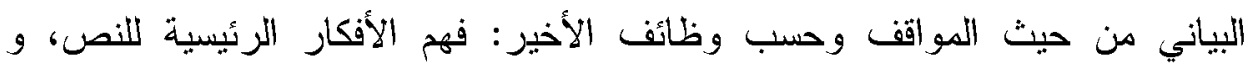
التفاصيل، و الصلات بين الأفكار، و تلخيص أفكار النص، وتحدبد معلومات بعينها

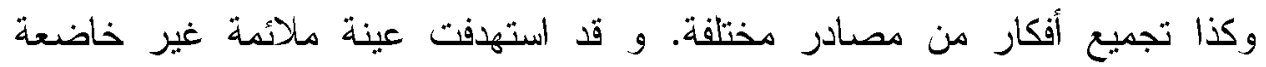
للإحتمالات مكونة من Oب مشاركا باستخدام أداة دلالية تفاضلية. وأظهرت النتائج التي فئي

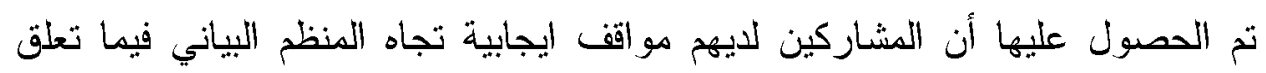
بالمهام المذكورة آنفا. كلمات مفتاحية: إستر اتجية القزاءة، منظم بياني، أداة دلالية تفاضلية 
The graphic organiser as a reading strategy: A semantic differential measurement of MA researchers' attitudes

\section{The graphic organiser as a reading strategy: A semantic differential measurement of MA researchers' attitudes}

\section{Dr Samia Kara,}

Department of English and Scientific Methods, GUC, Egypt Abstract: This paper reports on an evaluation of the graphic organiser as a reading strategy in terms of MA researchers' attitudes towards it (be they specialized in English or using English as a medium for writing their research). A question was raised in relation to their experience of using the graphic organiser in terms of attitudes and as per the latter's functions: understanding main ideas of a text, understanding details of a text, understanding connections among ideas in a text, summarising ideas of a text, locating specific information and synthesising ideas from various sources. A 25 participant non- probability convenience sample was targeted using a semantic differential tool. The results obtained demonstrated that the participants have positive attitudes towards the graphic organiser in relation to the aforementioned functions.

Keywords: Reading strategy, graphic organiser, semantic differential. 


\title{
The graphic organiser as a reading strategy: $\mathrm{A}$ semantic differential measurement of MA researchers' attitudes
}

\author{
Dr Samia Kara, \\ Department of English and Scientific Methods, GUC, Egypt
}

\section{Introduction}

The internet and the cumulative power of its instant flow have contributed largely to the exponential growth of human knowledge in all fields. Consequently, time is saved today in relation to searching for data as present generation researchers are equipped with notable hunting for information skills. However and if reading per se is not an issue for them, sifting data retrieved from texts is a cumbersome task. Indeed, MA researchers who are able to gather a bulky knowledge, find difficulties interacting with its meanings for the sake of writing a literature review. So, they resort to some strategies they may have encountered in their previous study years and of which the graphic organiser is part. The graphic organiser has been evidenced, as presented below, to be an efficient tool for reading in English and the question that might be asked here and in relation to MA researchers be they specialized in English or using English as a medium for writing their research should not come in terms of usefulness but in terms of attitudes it might trigger. In other words, how was their experience of using the graphic organiser in terms of attitudes in relation to:

- understanding main ideas of a text,

- understanding details of a text,

- understanding connections among ideas in a text, 
The graphic organiser as a reading strategy: A semantic differential measurement of MA researchers' attitudes

- summarising ideas of a text,

- locating specific information and

- synthesising ideas from various sources?

\section{Literature review}

\subsection{Knowledge}

Tackling the notion of knowledge has all the time proved to be a difficult task in the sense of it being so inclusive and multifaceted. Consequently, there always emerges a need to categorise it for the sake of a better understanding of its complexities. One classification is that of Alexander, Schallert and Hare (1991) who saw it in terms of content, domain and discipline. DiCecco and Gleason (2002) explained these categories by stating that whereas knowledge as content is factual and can be formally or informally gathered about the world around us, and whereas domain knowledge targets concepts for formal and systematic learning, discipline knowledge occurs when a specialised understanding takes place. Thus and as a matter of fact, categorising knowledge in that way presupposes the creation of links among its units. The latter may help learners, according to the above-mentioned authors, to attain another level which is that of relational knowledge.

Compatibly and at the storage level, knowledge is viewed by the dual coding theory in psychology (Paivio, 1969) as linguistic and non-linguistic/ imagery. Linguistic knowledge is processed in terms of verbal and symbolic representations of concrete objects as well as abstract ideas, and with regard to a verbal system that includes elements such as visual, auditory, and articulatory codes (Clarke \& Paivio, 1991). Conversely, non-linguistic representations have to do with non-linguistic objects and events (Clarke \& Paivio, 1991). For instance, when one learns in English the words "dog" or 
"cat", s/he knows their semantic equivalents in his/her native language. In addition, s/he also learns how to write them using English letters. Thus, s/he represents them linguistically. Nonlinguistic representation, for its part, would mean that an actual image of the dog or cat is created in the mind and is associated with the target word. In fact and in Clarke and Paivio's (1991) words, non-verbal representations comprise a set of images that are specific to shapes (e.g., molecule model), environmental sounds (e.g., a bell), actions ( drawing) as well as skeletal or visceral sensations (e.g., heart beat) to name a few.

When it comes to reading and texts, Clarke and Paivio (1991) maintained that if image arousal is encouraged, text meaning/ comprehension increases. Thus, the more both of linguistic and nonlinguistic modes of knowledge storage are used, the better knowledge is conceived of and remembered (Marzano, Gaddy \& Dean, 2000). Marzano, Gaddy \& Dean (2000) went further explaining that encouraging students to create non-linguistic representations invigorates and augments activity in the brain, the result being a better understanding. This might be fulfilled, on the strength of the same authors, in three ways: creating graphic representations, making physical models and generating pictures.

Within the reading skill scope, students encounter texts that are mostly content knowledge based. In this respect, their failure to process factual concepts is not only due to a shortage in their competence in the English language but also, and may be most importantly, to their failure to process information in terms of concepts and concept hierarchy. Graphic organisers constitute a way to remedy the situation by engaging the students in nonlinguistic representations of the targeted texts through their reconstruction in a pictorial form. 
The graphic organiser as a reading strategy: A semantic differential measurement of MA researchers' attitudes

\subsection{Graphic organiser}

A graphic organiser (GO) is an intelligible diagram made of graphically connected statements of information organised visuospatially (Horton, Lovitt \& Bergrud, 1990). They aim at facilitating the learning of text-mediated material through transcoding the content, structure and basic conceptual associations in a spatial arrangement (Darch \& Eaves, 1986).

Also called visual displays, graphical representations, tree diagrams, structure overviews, network representations, and adjunct aids, GOs- which can be deployed in various types of texts, are mainly made of words that point to relations among the concepts present in the text in a spatial organisation and portray the plan of the latter (Manoli \& Papadopoulou, 2012). These links are exhibited with arrows and symbols that emphasise connections (BartonArwood \& Little, 2013).Thus, GOs help making learners move towards relational knowledge that takes place after the aforementioned links among concepts are assimilated (DiCecco \& Gleason, 2002).

Originally, GOs were rooted in Ausubel's (1968) theory of meaningful verbal learning wherein he proposed that advance organisers (that is, before reading) are used to activate learners' prior knowledge for the sake of assimilating the new information (Manoli \& Papadopoulo, 2012). Thus, GOs were initially used to enhance learners' readiness for reading activities (Horton, Lovill \& Bergerud, 1990). That was the beginning of an outgrowth of research in the realm of spatial learning strategies (DiCecco \& Gleason, 2002). Today, this reading strategy ranks second on Marzano's High Yield Instructional Strategies scale (Marzano, Pickering \& Pollock, 2001) with 34 percentile gain (as a result of a meta-analysis of around 100 independent studies, nine strategies have been identified and ranked as having the greatest positive effect on student achievement). 
GOs have received considerable interest on the part of researchers in the realm of reading comprehension. For example, Jones et al. (1988, cited in Torres, 2015) asserted that they help greatly learners in understanding main ideas and details included in a text, connections existing among them as well as vague aspects as they encourage them to process texts for the sake of understanding, summarising and synthesising its difficult ideas. Additionally and in Robinson et al.'s (2006, cited in Torres, 2015) words, GOs also help learners grasp transverse relations that cannot be reached within the linguistic form of the text.

For their part, Manoli and Papadoupoulo (2012, p.351) maintained that research in the realm of first language acquisition and in relation to text comprehension showed that GOs can help learners:

- develop their reading comprehension skills as they help them recognise, shape and remember key ideas,

- develop their skills in detecting precise data,

- integrate the acquired knowledge in writing,

- visualise the text structure,

- raise their awareness of higher level organisation very needed in comprehension, and

- develop their summarisation skills.

In addition to their effects on first language acquisition, GOs were also found to have effects on second language learning by research (Manoli \& Papadoupoulo, 2012, p. 353) in terms of:

- increase in the sum of material recalled,

- better performance in summarisation skills,

- better skills in self-efficacy and self-monitoring, and

- better reading comprehension of sentences (more than the sentential display).

Although a considerable research bulk has demonstrated the benefits of using GOs, one cannot be completely assertive about 
The graphic organiser as a reading strategy: A semantic differential measurement of MA researchers' attitudes

their results. Indeed and as indicated by Kim, Vaughn, Wanzek \& Wei (2004), inconclusive findings are to be seen as being due to disparities in mediation designs, instructional practices and methodology issues. For instance and always on behalf of these same authors, it has been noted that text variables (type, content, level and originators - be they students or teachers), position (before and after text), as well as outcome measures play a vital role in result differences. Taking position into consideration, GOs that were constructed by students and positioned after the texts were proved to have greater effects especially when used for a long time (Kim, Vaughn, Wanzek \& Wei 2004).

The Education Bureau of Hong Kong (2016) emphasised the benefits of GOs for both students and teachers. Indeed, GOs were found to help learners to comprehend the part to whole concept, indicate relationships, elucidate and bring together ideas, increase memory, understand texts and different points of view. As to teachers, GOs helped them to explain relationships existing in the content, boost their lesson interactivity, support their visual learners in the acquisition of information, motivate students and support them in prewriting techniques as well as assess their knowledge.

When it comes to GOs typology, a variety of models have been proposed in the literature in accordance to their appearance and displayed relationships (Manoli \& Papadopoulo, 2012). Indeed, they can come in the form of a story map -including elements such as characters, time, setting..., a matrix - which gathers all the information within its square, a semantic map -wherein words and ideas are arranged around a central keyword or idea, a concept map - wherein concepts are enclosed in boxes that are linked by lines, a knowledge map - which is two-dimensional and made of node-link node assemblies, a tree diagram - which rely on hierarchy in terms of relationships among its components, and a Venn diagram - which 
is made of two or more overlapping circles (Manoli \& Papadopoulo, 2012). The aforementioned types have been summarised by Kools, Van De Wiel, Ruiter, Critis \& Kok (2006) in three forms: matrices, network maps and hierarchical tree diagrams.

GOs were also classified by the Education Bureau of Hong Kong (2016, p.8) into:

- cyclical GOs showing the sequence of events in a process

- hierarchical GOs showing the relation between a concept and its subordinates

- sequential GOs showing chronology of events and

- conceptual GOs showing concepts and their supporting facts.

When GOs are used in whatever form, they always constitute knowledge facilitating tools that induce reactions on the part of their users. These reactions can be described in terms of attitudes.

\subsection{Attitudes}

Attitudes have been the subject of study of many scholars who approached them through description, measurement, polls, theories and experiments (Oskamp \& Schultz, 2005). At the very beginning, an attitude used to point to a posture of the body; then, it came to mean a posture of the mind (Oskamp \& Schultz, 2005). In other words, it moved from a concrete designation to a more abstract conceptualisation operating at the level of the psyche. Allport (1935, p.810) defined it in a comprehensive way stating that it is 'a mental or neural state of readiness organised through experience', the key word being 'readiness' which means a state of being prepared to react in a predefined way toward a particular target. The latter can be embodied in people, places, things, actions, situations and ideas most commonly known as attitude objects (Oskamp \& Schultz, 2005).

Another definition of attitude has been embodied in approaches that view it as a predisposition that is learnt (Fishbein \& 
The graphic organiser as a reading strategy: A semantic differential measurement of MA researchers' attitudes

Ajzen, 1975). A third group of theorists used the term 'evaluation' to pinpoint attitude stating that it targets a specific entity dis/favouring it (Eagly \& Chaiken, 1993) and summarises its object of thought (Bohner, Wanke \& Michaela, 2002).

Consequently, an attitude is a complex notion that encompasses many facets which can be grouped into cognitive, affective and behavioural components (Triandis, 1975). The cognitive components are concerned with ideas one might have about the attitude object. For example, 'cats are very intelligent'. As to affective components, they come in relation to emotions one might hold towards an attitude object. For instance, 'to have a cat at home is a real pleasure'. For their part, behavioural components refer to one's penchants in terms of conduct towards an attitude object. For example, 'I will bring many cats at home if I could afford it financially'.

Attitudes are pinpointed as being either explicit or implicit. Whereas explicit attitudes are intentional and self- conveyed, implicit ones are construed from individuals' performance in tests (Gawronski \& Bodenhaussen, 2006).

\section{Methodology}

\subsection{Design}

This research was descriptive in the sense that it targeted GOs users' attitudes towards their experience -and in relation to their MA literature review, in terms of evaluation using a semantic differential tool.

\subsection{Participants}

The research being exploratory, the sample was a nonprobability convenience one (Lavraks, 2008) targeting elements that met two criteria: 
- Students who undertook an MA research in relation to / using the English language (be it fulfilled or still going on) and who needed to review the literature in relation to their topic for the sake of summarising and syntesising ideas present in this type of extensive reading,

- Those who declared having resorted to using a GO during their literature review phase.

The respondents were twenty five researchers in the fields of applied linguistics (5), literature (5), education (5), translation (2), educational leadership (2), business (2), comparative education (1), communications (1), special needs education (1), TESOL (1). They were affiliated to the universities: Cairo, Ain Shams, Helwan, AUC, GUC (Egypt), Constantine (Algeria), London, (GB), Wyoming (USA) Sorbonne (France) and Bremen (Germany). 11 of them have already finished their MA and 14 are still working on their degree.

\subsection{Research instrument}

The research means adopted in this study is the semantic differential (SD). SD is an instrument that was developed by Osgood, Suci and Tannenbaum (1957) for the sake of evaluating people's responses to concepts and meanings by rating those using bipolar adjective scales. Numerous studies made use of the SD to measure attitudes in a variety of contexts (Heise, 1975).

Purposefully, the ratings attained via the SD were structured into three dimensions, namely, evaluation, potency and activity. The latter have emerged after Osgood (1950s; cited in Doyle \& Bottomley, 2010) analysed a huge number of concepts that were assessed against a big number of bipolar adjectives. The result was an accurate description of meaning present in the adjectives in terms of the above mentioned dimensions which are in fact independent factors known as EPA. E (evaluation) is represented by adjective pairs such as 'good-bad', $\mathrm{P}$ (potency) is exemplified by adjectives

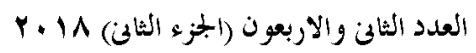


The graphic organiser as a reading strategy: A semantic differential measurement of MA researchers' attitudes

pairs such as 'strong-weak', and A (activity) is illustrated by adjective pairs like 'slow-fast'.

According to Doyle \& Bottomley (2010), the SD is valued for its coverage as it has the capacity of pinpointing any set of bipolar adjectives. In addition and always according to these same authors, meaning is adequately represented for the benefit of economy, cross-culturality, cross-application and primacy thanks to the EPA dimensions. The adaptation that was made of the SD targeted six components in relation to using the GO: understanding main ideas of a text, understanding details of a text, understanding connections among ideas in a text, summarizing ideas of a text and synthesising ideas from various sources. The SD also used a scale of -3 to 3 and the adjective pairs: bad-good/ unhelpful-helpful for evaluation, inefficient-efficient/ weak-strong/ for potency and passive-active/ slow-fast for activity.

40 SDs were sent to the participants. 31 were returned of which 6 were disregarded because of missing ratings. The final sample was made of 25 SDs.

\section{Results}

Table 1. Results

\begin{tabular}{|c|c|c|c|c|c|c|c|c|c|c|c|c|c|c|c|c|c|c|}
\hline \multicolumn{19}{|c|}{ The experience of using graphic organisers to: } \\
\hline \multirow[t]{2}{*}{$\mathrm{N}$} & \multicolumn{3}{|c|}{$\mid \begin{array}{l}\text { Understand } \\
\text { main ideas of } \\
\text { a text }\end{array}$} & \multicolumn{3}{|c|}{$\begin{array}{l}\text { Understand } \\
\text { details of a } \\
\text { text }\end{array}$} & \multicolumn{3}{|c|}{$\begin{array}{l}\text { Understand } \\
\text { connections } \\
\text { among ideas } \\
\text { of a text }\end{array}$} & \multicolumn{3}{|c|}{$\begin{array}{l}\text { Summarise } \\
\text { ideas of a text }\end{array}$} & \multicolumn{3}{|c|}{$\begin{array}{l}\text { Locate } \\
\text { specific } \\
\text { information }\end{array}$} & \multicolumn{3}{|c|}{$\mid \begin{array}{ll}\text { Synthesise } \\
\text { ideas from } \\
\text { various } \\
\text { sources }\end{array}$} \\
\hline & E1 & $\mathrm{P} 1$ & A1 & E2 & $\mathrm{P} 2$ & A2 & E3 & P3 & A3 & E4 & $\mathrm{P} 4$ & A4 & E5 & P5 & A5 & E6 & P6 & A6 \\
\hline 1 & 1.0 & 1.0 & 0.0 & $\mid-1.0$ & -2.0 & $\mid-2.0$ & 3.0 & 2.0 & 0.5 & 3.0 & 2.5 & 2.0 & $\mid-2.0$ & -2.0 & $\mid-2.0$ & $\mid 2.0$ & $\mid 2.0$ & $\mid 2.0$ \\
\hline 2 & 3.0 & 3.0 & 3.0 & 3.0 & 3.0 & 3.0 & 3.0 & 3.0 & 3.0 & 3.0 & 3.0 & 3.0 & 3.0 & 3.0 & 3.0 & 3.0 & 3.0 & 3.0 \\
\hline 3 & 1.0 & 1.5 & 0.5 & 1.5 & 1.5 & 1.0 & 1.0 & 1.0 & 0.0 & 2.0 & 0.5 & 0.5 & 2.0 & 1.5 & 1.0 & 0.5 & 1.0 & 0.5 \\
\hline 4 & 1.5 & 3.0 & 2.0 & 2.0 & 3.0 & 2.5 & 2.5 & 2.0 & 2.0 & 2.5 & 2.5 & 3.0 & 2.0 & 2.0 & 2.0 & 2.0 & 3.0 & 2.5 \\
\hline
\end{tabular}

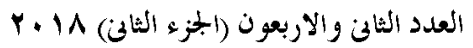




\section{Dr. Samia Kara}

\begin{tabular}{||c|c||c|c|c|c|c|c|c|c|c|c|c|c|c|c|c|c|c|||||}
\hline \hline 5 & -0.5 & -3.0 & -3.0 & -0.5 & -1.0 & 0.0 & 0.0 & -3.0 & -3.0 & 3.0 & -3.0 & -3.0 & -0.5 & -3.0 & -3.0 & 3.0 & 3.0 & 3.0 \\
\hline 6 & 1.5 & 2.0 & 2.5 & 2.0 & 1.5 & 2.0 & 2.0 & 2.0 & 2.0 & 1.0 & 1.5 & 2.0 & 2.5 & 2.0 & 3.0 & 2.5 & 2.5 & 2.0 \\
\hline 7 & 2.5 & 1.5 & 2.5 & 2.5 & 1.5 & 1.5 & 2.5 & 2.0 & 1.5 & 3.0 & 2.0 & 3.0 & 1.5 & 1.5 & 2.0 & 3.0 & 2.0 & 2.5 \\
\hline \hline 8 & 1.0 & 0.5 & 0.5 & 1.0 & 0.5 & 1.0 & 2.0 & 2.0 & 2.0 & 2.0 & 2.0 & 2.0 & 1.0 & 1.0 & 1.0 & 2.0 & 2.0 & 2.0 \\
\hline 9 & 2.5 & 1.0 & 1.0 & 2.0 & 2.0 & 2.0 & 1.5 & 2.0 & 0.5 & 1.0 & 1.5 & 1.0 & 1.5 & 2.0 & 2.0 & 1.5 & 1.0 & 2.0 \\
\hline 10 & -0.5 & 0.5 & -1.0 & 0.5 & 0.0 & 0.0 & -0.5 & 0.0 & 0.0 & -0.5 & 0.0 & 0.0 & 0.5 & 0.0 & 0.0 & 0.0 & 0.0 & 0.0 \\
\hline 11 & 2.0 & 2.5 & 3.0 & 2.0 & 2.0 & 2.0 & 3.0 & 2.0 & 3.0 & 1.5 & 1.0 & 2.0 & 3.0 & 3.0 & 3.0 & 1.5 & 1.0 & 1.0 \\
\hline 12 & 3.0 & 3.0 & 3.0 & 3.0 & 2.0 & 1.5 & 0.5 & 1.0 & 1.0 & 2.0 & 2.0 & 2.0 & 1.5 & 2.0 & 2.0 & 1.0 & 1.0 & 1.0 \\
\hline \hline 13 & 1.5 & 1.5 & 1.0 & -1.0 & 0.0 & 0.0 & 2.0 & 1.0 & 1.0 & 1.0 & 1.0 & 1.0 & 2.0 & 2.0 & 2.0 & 1.0 & 1.0 & 1.0 \\
\hline \hline 14 & 3.0 & 3.0 & 3.0 & 3.0 & 3.0 & 3.0 & 3.0 & 3.0 & 3.0 & 3.0 & 3.0 & 3.0 & 3.0 & 3.0 & 3.0 & 3.0 & 3.0 & 0.0 \\
\hline 15 & 3.0 & 2.5 & 2.0 & 3.0 & 2.5 & 2.0 & 2.0 & 2.0 & 2.0 & 2.0 & 2.0 & 2.0 & 2.0 & 2.0 & 1.5 & 3.0 & 3.0 & 2.5 \\
\hline 16 & 3.0 & 3.0 & 3.0 & 2.0 & 2.0 & 2.0 & 1.5 & 1.5 & 1.5 & 2.0 & 2.0 & 2.0 & 1.0 & 1.0 & 1.0 & 1.0 & 1.0 & 1.0 \\
\hline 17 & 2.5 & 1.0 & 1.5 & 2.0 & 1.0 & 1.5 & 2.0 & 1.5 & 1.5 & 2.0 & 1.0 & 2.0 & 1.5 & 1.5 & 1.5 & 2.0 & 2.0 & 1.5 \\
\hline 18 & 2.5 & 3.0 & 2.0 & 1.5 & 2.0 & 2.0 & 3.0 & 3.0 & 2.0 & 3.0 & 3.0 & 2.5 & 2.5 & 3.0 & 2.5 & 3.0 & 3.0 & 2.5 \\
\hline 19 & 3.0 & 3.0 & 3.0 & 3.0 & 3.0 & 3.0 & 2.0 & 1.5 & 1.5 & 3.0 & 3.0 & 3.0 & 2.5 & 0.0 & 0.0 & 3.0 & 3.0 & 3.0 \\
\hline 20 & 3.0 & 3.0 & 1.5 & 3.0 & 3.0 & 2.5 & 2.0 & 1.5 & 1.5 & 3.0 & 3.0 & 3.0 & 3.0 & 3.0 & 3.0 & 2.0 & 1.5 & 3.0 \\
\hline 21 & 3.0 & 3.0 & 1.5 & 3.0 & 3.0 & 2.5 & 2.0 & 1.5 & 1.5 & 3.0 & 3.0 & 3.0 & 3.0 & 3.0 & 3.0 & 2.0 & 1.5 & 3.0 \\
\hline 22 & 3.0 & 3.0 & 1.5 & 3.0 & 3.0 & 1.5 & 3.0 & 3.0 & 3.0 & 3.0 & 2.5 & 2.0 & 1.5 & 1.0 & 1.5 & 2.0 & 2.5 & 2.5 \\
\hline 23 & 1.5 & 0.5 & 0.0 & 2.0 & 1.0 & 1.0 & 0.0 & 0.0 & 0.0 & 2.0 & 2.0 & 2.0 & 1.0 & 1.0 & 1.0 & 0.0 & 0.0 & 0.0 \\
\hline 24 & 2.0 & 2.0 & 2.0 & 2.0 & 2.0 & 2.0 & 2.0 & 2.0 & 2.0 & 1.0 & 1.0 & 1.0 & 1.0 & 1.0 & 1.0 & 1.0 & 1.0 & 1.0 \\
\hline 25 & 2.0 & 2.0 & 2.0 & 3.0 & 3.0 & 3.0 & 2.0 & 2.0 & 2.0 & -1.0 & -1.0 & -1.0 & 2.0 & 2.0 & 2.0 & 2.0 & 2.0 & 2.0 \\
\hline \hline
\end{tabular}

Table 2. SD reliability

\begin{tabular}{|l|l|l|l|l|l|l|l|}
\cline { 2 - 8 } \multicolumn{1}{c|}{} & Q1 & Q2 & Q3 & Q4 & Q5 & Q6 & SD \\
\hline Cronbach $\alpha$ & $\mathbf{0 . 9 2}$ & $\mathbf{0 . 9 6}$ & $\mathbf{0 . 9 3}$ & $\mathbf{0 . 8 6}$ & $\mathbf{0 . 9 6}$ & $\mathbf{0 . 9 0}$ & $\mathbf{0 . 9 4}$ \\
\hline
\end{tabular}

The thorough results of the SD are reported in table1. The reliability of the SD was established by the Cronbach's alpha (Nunnally \&Berstein, 1994) which was equal to 0.945 for the whole tool and which was $[0.86,0.96]$ for individual questions as shown in table 2 . 
The graphic organiser as a reading strategy: A semantic differential measurement of MA researchers' attitudes

\subsection{Question1: Understanding main ideas of a text}

Table 3. Descriptive statistics for question 1

\begin{tabular}{|c|c|c|c|c|c|c|}
\hline Dimension & $\mathrm{N}$ & Min. & Max. & Median & Mean & \begin{tabular}{|l|} 
Std. \\
Deviation
\end{tabular} \\
\hline E1 & 25 & -.50 & 3.00 & 2.50 & 2.0400 & 1.05000 \\
\hline P1 & 25 & -3.00 & 3.00 & 2.00 & 1.8800 & 1.37901 \\
\hline A1 & 25 & -3.00 & 3.00 & 2.00 & 1.5200 & 1.44684 \\
\hline Valid N (listwise) & 25 & & & & & \\
\hline
\end{tabular}

Figure 1. Question 1 dimensions

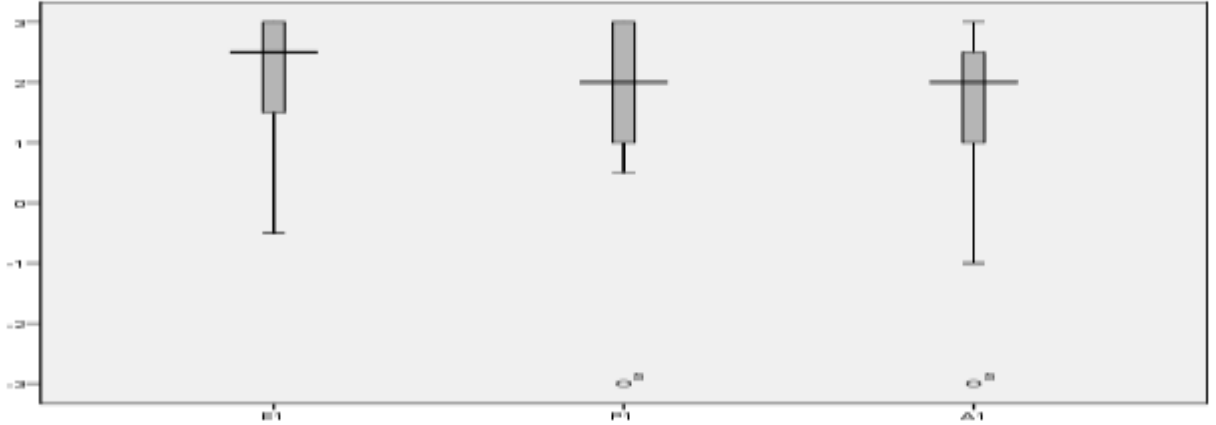

The examination of the data displayed in table 3 and figure 1 points to the subsequent results:

- The median is approximately the same for the three dimensions: 2.5 for evaluation, 2 for potency and 2 for activity,

- All three dimensions share the same maximum (3).

- Whereas the minimum is the same for potency and activity (-3), it equals $\quad-0.5$ for evaluation,

- Evaluation and activity are skewed to the right (higher values) while potency is symmetrical,

- The evaluation and activity results are more consistent than the potency as their interquartile is smaller than the latter's, 


\section{Dr. Samia Kara}

- The standard deviations of evaluation, potency and activity are sequentially $1.05,1.37$ and 1.44 ,

- Figure 1 shows potential outliers in potency and activity,

- $75 \%$ of the respondents scored $[1.5,3]$ in evaluation,

- $75 \%$ of the respondents scored $[1,3]$ in potency and

- $75 \%$ of the respondents scored $[1,3]$ in activity.

Table 9. Question 1 correlations

\begin{tabular}{|ll|l|l|l|}
\hline & E1 & P1 & A1 \\
\hline E1 & Pearson Correlation & 1 & $.795^{* *}$ & $.815^{* *}$ \\
& Sig. (2-tailed) & .000 & .000 & .000 \\
& $\mathrm{~N}$ & 25 & 25 & 25 \\
\hline P1 & Pearson Correlation & $.795^{* *}$ & 1 & $.873^{* *}$ \\
& Sig. (2-tailed) & .000 & .000 & .000 \\
& N & 25 & 25 & 25 \\
\hline A1 & Pearson Correlation & $.815^{* *}$ & $.873^{* *}$ & 1 \\
& Sig. (2-tailed) & .000 & .000 & .000 \\
& N & 25 & 25 & 25 \\
\hline
\end{tabular}

**Correlation is significant at the 0.01 level (2-tailed).

In relation to internal correlations among the three dimensions and as shown in table 9 ,

- $\mathrm{r}(\mathrm{E} 1, \mathrm{P} 1)=0.795$

- $\mathrm{r}(\mathrm{E} 1, \mathrm{~A} 1)=0.815$

- $r(\mathrm{P} 1, \mathrm{~A} 1)=0.873$

\subsection{Question2: Understanding details of a text}

Table 4. Descriptive statistics for question 2

\begin{tabular}{|l|l|l|l|l|l|l|}
\hline Dimension & N & Min. & Max. & Median & Mean & $\begin{array}{l}\text { Std. } \\
\text { Deviation }\end{array}$ \\
\hline E2 & 25 & -1.00 & 3.00 & 2.00 & 1.9000 & 1.24164 \\
P2 & 25 & -2.00 & 3.00 & 2.00 & 1.7000 & 1.35401 \\
A2 & 25 & -2.00 & 3.00 & 2.00 & 1.6200 & 1.17509 \\
Valid N (listwise) & 25 & & & & & \\
\hline
\end{tabular}

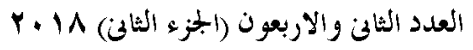

(109)

مجلة كلية التربية- جامعة عين شمس 
The graphic organiser as a reading strategy: A semantic differential measurement of MA researchers' attitudes

Figure 2. Question 2 dimensions

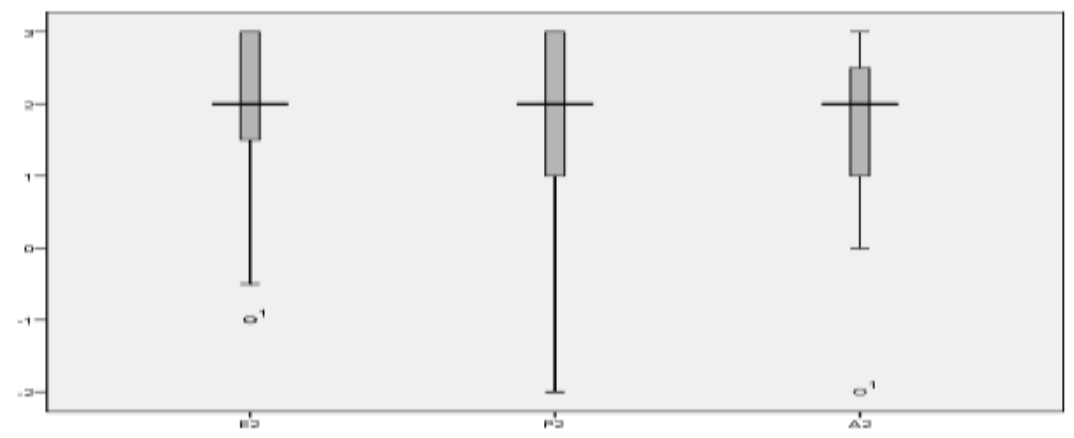

The examination of the data displayed in table 4 and figure 2 points to the subsequent results:

- The median is exactly the same for the three dimensions: 2 ,

- All three dimensions share the same maximum (3),

- Whereas the minimum is the same for potency and activity (-2), it equals -1 for evaluation,

- Evaluation is skewed to the left (lower values), potency is symmetrical and activity is skewed to the right (higher values),

- The evaluation and activity results are more consistent than the potency as their interquartile is smaller than the latter's,

- The standard deviations of evaluation, potency and activity are sequentially $1.24,1.35$ and 1.17 ,

- Figure 2 shows potential outliers in evaluation and activity,

- $75 \%$ of the respondents scored $[1.5,3]$ in evaluation,

- $75 \%$ of the respondents scored $[1,3]$ in potency and

- $75 \%$ of the respondents scored $[1,3]$ in activity.

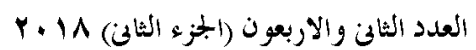

(110)

مجلة كلية التربية- جامعة عين شمس 


\section{Dr. Samia Kara}

Table 10. Question 2 correlations
\begin{tabular}{|ll|l|l|l|}
\hline & & E2 & P2 & A2 \\
\hline E2 & Pearson Correlation & 1 & $.911^{* *}$ & $.865^{* *}$ \\
& Sig. (2-tailed) & .000 & .000 & .000 \\
& N & 25 & 25 & 25 \\
\hline P2 & Pearson Correlation & $.911^{* *}$ & 1 & $.940^{* *}$ \\
& Sig. (2-tailed) & .000 & .000 & .000 \\
& N & 25 & 25 & 25 \\
\hline A2 & Pearson Correlation & $.865^{* *}$ & $.940^{* *}$ & 1 \\
& Sig. (2-tailed) & .000 & .000 & .000 \\
N & 25 & 25 & 25 \\
\hline
\end{tabular}

**. Correlation is significant at the 0.01 level (2-tailed).

In relation to internal correlations among the three dimensions and as shown in table 10 ,

- $\mathrm{r}(\mathrm{E} 2, \mathrm{P} 2)=0.911$

- $\mathrm{r}(\mathrm{E} 2, \mathrm{~A} 2)=0.865$

- $r(\mathrm{P} 2, \mathrm{~A} 2)=0.940$

\subsection{Question3: Understanding connections among ideas in a text}

Table 5. Descriptive statistics for question 3

\begin{tabular}{|l|l|l|l|l|l|l|}
\hline Dimension & & & & & & $\begin{array}{l}\text { Std. } \\
\text { Deviation }\end{array}$ \\
\hline E3 & 25 & -.50 & 3 & 2.00 & 1.8800 & 1.00291 \\
P3 & 25 & -3.00 & 3 & 2.00 & 1.5800 & 1.23895 \\
A3 & 25 & -3.00 & 3 & 1.50 & 1.4000 & 1.29099 \\
Valid N (listwise) & 25 & & & & & \\
\hline
\end{tabular}

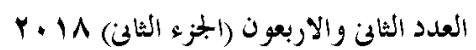


The graphic organiser as a reading strategy: A semantic differential measurement of MA researchers' attitudes

Figure 3. Question 3 dimensions

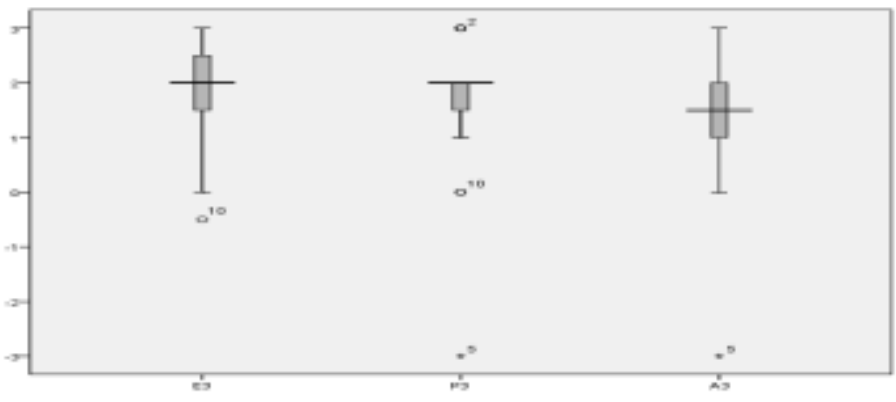

The examination of the data displayed in table 5 and figure 3 points to the subsequent results:

- The median is approximately the same for the three dimensions: 2 for evaluation, 2 for potency and 1.5 for activity,

- All three dimensions share the same maximum (3),

- Whereas the minimum is the same for potency and activity (-3), it equals -0.5 for evaluation,

- Evaluation is skewed to the left (lower values), potency is symmetrical and activity is skewed to the right (higher values),

- The evaluation and activity results are less consistent than the potency as their interquartile is larger than the latter's,

- The standard deviations of evaluation, potency and activity are sequentially $1,1.23$ and 1.29 ,

- Figure 3 shows potential outliers in evaluation and potency,

- $75 \%$ of the respondents scored $[1.5,3]$ in evaluation,

- $75 \%$ of the respondents scored $[1.5,2]$ in potency and

- $75 \%$ of the respondents scored $[1,2]$ in activity. 
Dr. Samia Kara

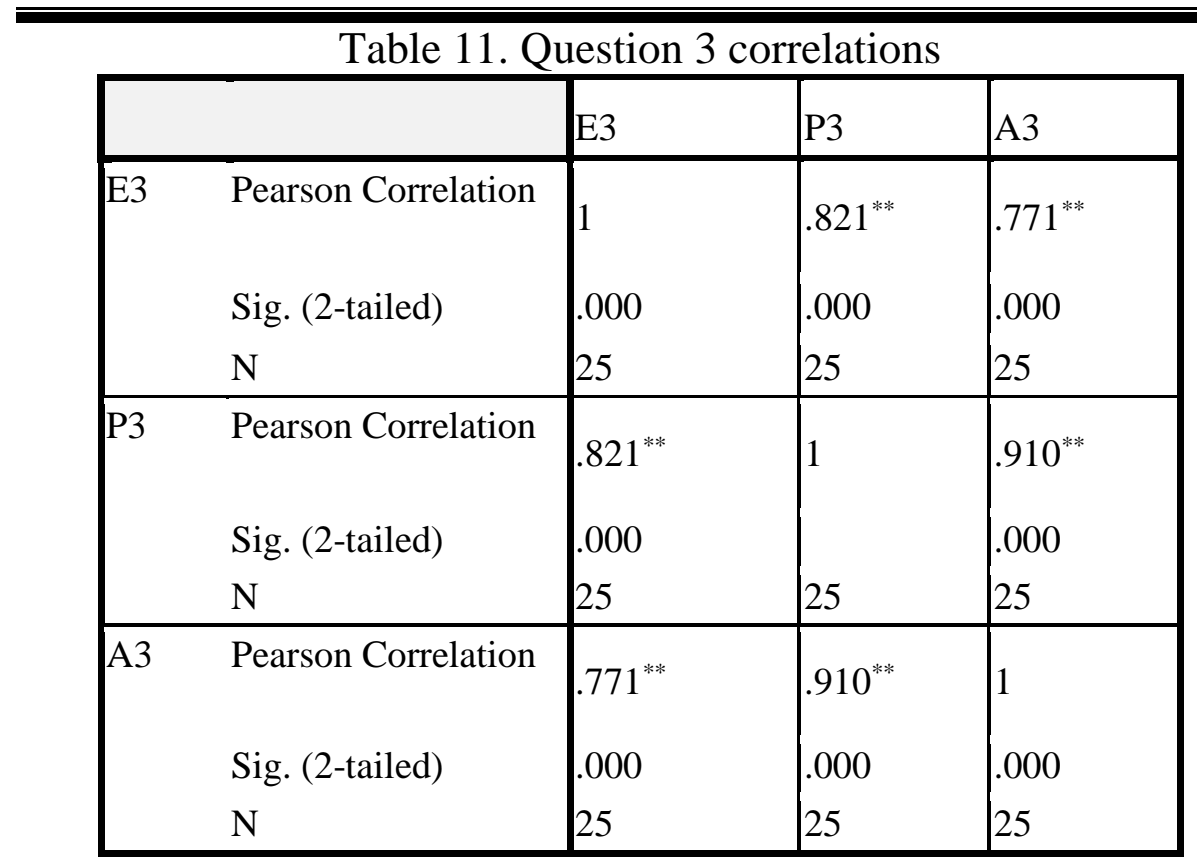

**. Correlation is significant at the 0.01 level (2-tailed).

In relation to internal correlations among the three dimensions and as shown in table 11 ,

$$
\begin{array}{ll}
\text { - } & \mathrm{r}(\mathrm{E} 3, \mathrm{P} 3)=0.821 \\
\text { - } & \mathrm{r}(\mathrm{E} 3, \mathrm{~A} 3)=0.771 \\
\text { - } & \mathrm{r}(\mathrm{P} 3, \mathrm{~A} 3)=0.910
\end{array}
$$

\begin{tabular}{|c|c|c|c|c|c|c|}
\hline Dimension & $\mathrm{N}$ & Min. & Max. & Median & Mean & $\begin{array}{l}\text { Std. } \\
\text { Deviation }\end{array}$ \\
\hline $\mathrm{E} 4$ & 25 & -1.00 & 3.00 & 2.00 & 2.0200 & 1.11318 \\
\hline P4 & 25 & -3.00 & 3.00 & 2.00 & 1.6400 & 1.41804 \\
\hline A4 & 25 & -3.00 & 3.00 & 2.00 & 1.7200 & 1.42215 \\
\hline Valid N (listwise) & 25 & & & & & \\
\hline
\end{tabular}

\subsection{Question4: Summarising ideas of a text}

Table 6. Descriptive statistics for question 4

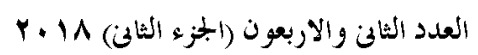


The graphic organiser as a reading strategy: A semantic differential measurement of MA researchers' attitudes

Figure 4. Question 4 dimensions

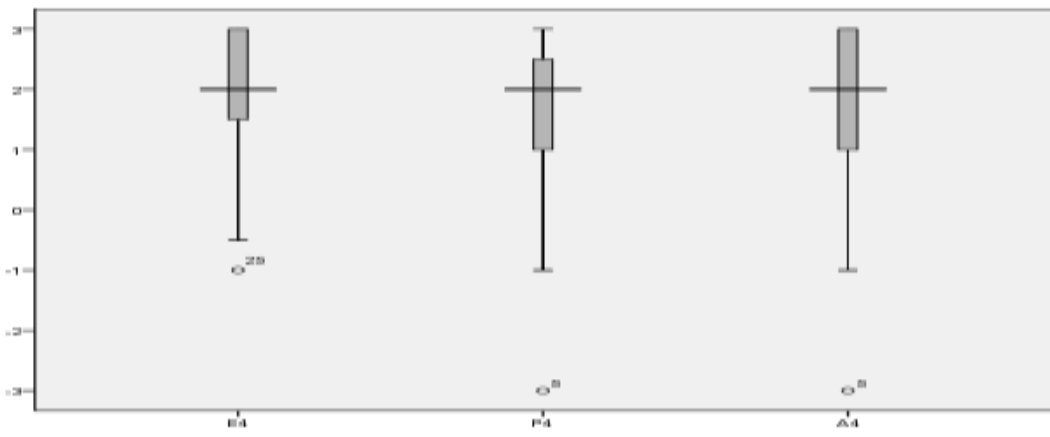

The examination of the data displayed in table 6 and figure 4 points to the subsequent results:

- The median is exactly the same for the three dimensions: 2 ,

- All three dimensions share the same maximum (3),

- Whereas the minimum is the same for potency and activity (-3), it equals -1 for evaluation,

- Evaluation is skewed to the left (lower values), potency is skewed to the right (higher values) and activity is symmetrical,

- The evaluation and potency results are fairly more consistent than the activity as their interquartile is smaller than the latter's,

- The standard deviations of evaluation, potency and activity are sequentially $1.11,1.42$ and 1.42 ,

- Figure 4 shows potential outliers in evaluation, potency and activity,

- $75 \%$ of the respondents scored $[1.5,3]$ in evaluation,

- $75 \%$ of the respondents scored $[1,3]$ in potency and

- $75 \%$ of the respondents scored $[1,3]$ in activity. 
Dr. Samia Kara

\begin{tabular}{|ll|l|l|l|}
\hline \hline \multicolumn{4}{|c|}{ Table 12. Question 4 correlations } \\
\hline E4 & Pearson Correlation & 1 & $.526^{* *}$ & $.504^{* *}$ \\
& Sig. (2-tailed) & .000 & .007 & .010 \\
& & & 25 & 25 \\
\hline P4 & Pearson Correlation & $.526^{* *}$ & 1 & $.955^{* *}$ \\
& Sig. (2-tailed) & .007 & .000 & .000 \\
& N & 25 & 25 & 25 \\
\hline A4 & Pearson Correlation & $.504^{*}$ & $.955^{* *}$ & 1 \\
& Sig. (2-tailed) & .010 & .000 & .000 \\
& N & 25 & 25 & 25 \\
\hline
\end{tabular}

**. Correlation is significant at the 0.01 level (2-tailed).

In relation to internal correlations among the three dimensions and as shown in table 12 ,

- $\mathrm{r}(\mathrm{E} 4, \mathrm{P} 4)=0.526$

- $\mathrm{r}(\mathrm{E} 4, \mathrm{~A} 4)=0.504$

- $\mathrm{r}(\mathrm{P} 4, \mathrm{~A} 4)=0.955$

\subsection{Question5: Locating specific information}

Table 7. Descriptive statistics for question 5

\begin{tabular}{|l|l|l|l|l|l|l|}
\hline Dimension & & N & Max. & Median & Mean & $\begin{array}{l}\text { Std. } \\
\text { Deviation }\end{array}$ \\
\hline E5 & 25 & -2.00 & 3.00 & 2.00 & 1.6800 & 1.17154 \\
P5 & 25 & -3.00 & 3.00 & 2.00 & 1.4600 & 1.49248 \\
A5 & 25 & -3.00 & 3.00 & 2.00 & 1.4800 & 1.50333 \\
Valid N (listwise) & 25 & & & & & \\
\hline
\end{tabular}

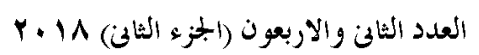


The graphic organiser as a reading strategy: A semantic differential measurement of MA researchers' attitudes

Figure 5. Question 5 dimensions

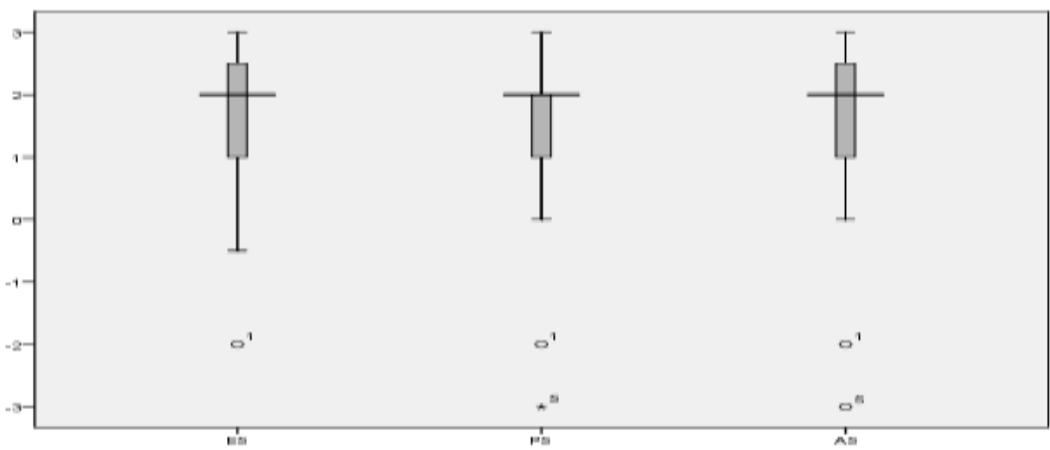

The examination of the data displayed in table 7 and figure 5 points to the subsequent results:

- The median is exactly the same for the three dimensions: 2 ,

- All three dimensions share the same maximum (3),

- Whereas the minimum is the same for potency and activity (-3), it equals -2 for evaluation,

- Evaluation and activity are skewed to the right (higher values) whereas potency is skewed to the left (lower values),

- The evaluation and activity results are less consistent than the potency as their interquartile is larger than the latter's,

- The standard deviations of evaluation, potency and activity are sequentially 1.17, 1.49 and 1.5 ,

- Figure 5 shows potential outliers in evaluation and activity,

- $75 \%$ of the respondents scored $[-0.5,3]$ in evaluation,

- $75 \%$ of the respondents scored $[0,3]$ in potency and

- $75 \%$ of the respondents scored $[0,3]$ in activity. 


\section{Dr. Samia Kara}

\begin{tabular}{l}
\hline \hline Table 13. Question 5 correlations \\
\begin{tabular}{|ll|l|l|l|}
\hline & E5 & P5 & A5 \\
\hline E5 & Pearson Correlation & 1 & $.874^{* *}$ & $.866^{* *}$ \\
& Sig. (2-tailed) & & .000 & .000 \\
& $\mathrm{~N}$ & 25 & 25 & 25 \\
\hline P5 & Pearson Correlation & $.874^{* *}$ & 1 & $.979^{* *}$ \\
& Sig. (2-tailed) & .000 & & .000 \\
& $\mathrm{~N}$ & 25 & 25 & 25 \\
\hline A5 & Pearson Correlation & $.866^{* *}$ & $.979^{* *}$ & 1 \\
& Sig. (2-tailed) & .000 & .000 & \\
& $\mathrm{~N}$ & 25 & 25 & 25 \\
\hline
\end{tabular}
\end{tabular}

**. Correlation is significant at the 0.01 level (2-tailed).

In relation to internal correlations among the three dimensions and as shown in table 13,

- $r(E 5, \mathrm{P} 5)=0.874$

- $r(E 5, A 5)=0.866$

- $r(\mathrm{P} 5, \mathrm{~A} 5)=0.979$

\subsection{Question6: Synthesising ideas from various sources}

Table 8. Descriptive statistics for question 6

\begin{tabular}{|l|l|l|l|l|l|l|}
\hline Dimension & & & & & & $\begin{array}{l}\text { Std. } \\
\text { Deviation }\end{array}$ \\
\hline E6 & 25 & .00 & 3.00 & 2.00 & 1.8800 & 0.94956 \\
P6 & 25 & .00 & 3.00 & 2.00 & 1.8400 & 0.96523 \\
A6 & 25 & .00 & 3.00 & 2.00 & 1.7800 & 1.01119 \\
Valid N (listwise) & 25 & & & & & \\
\hline
\end{tabular}


The graphic organiser as a reading strategy: A semantic differential measurement of MA researchers' attitudes

Figure 6. Question 6 dimensions

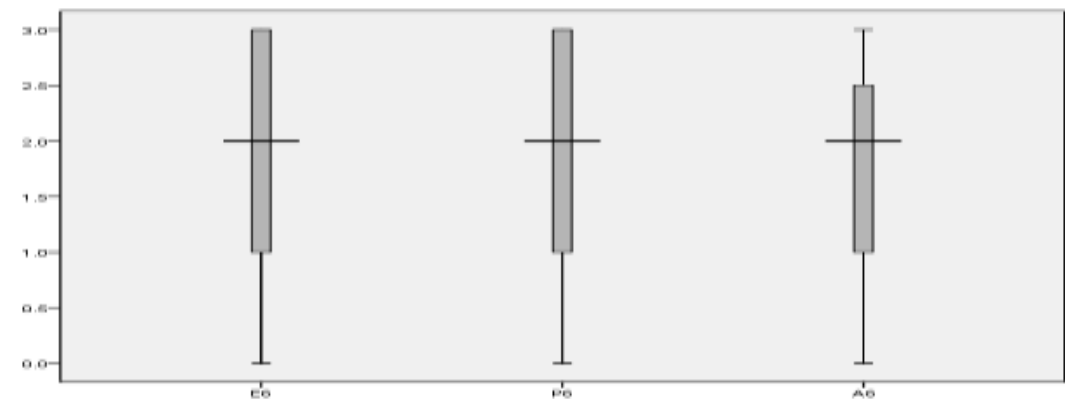

The examination of the data displayed in table 8 and figure 6 points to the subsequent results:

- The median is exactly the same for the three dimensions: 2 ,

- All three dimensions share the same maximum (3),

- All three dimensions share the same minimum (0),

- Whereas evaluation and potency are symmetrical and activity is skewed to the right (higher values),

- The evaluation and potency results are less consistent than the activity as their interquartile is larger than the latter's,

- The standard deviations of evaluation, potency and activity are sequentially $0.95,0.96$ and 1.01 ,

- Figure 6 shows no potential outliers,

- $75 \%$ of the respondents scored $[1,3]$ in evaluation,

- $75 \%$ of the respondents scored $[1,3]$ in potency and

- $75 \%$ of the respondents scored $[1,3]$ in activity. 
Dr. Samia Kara

\begin{tabular}{|ll|l|l|l|}
\hline \multicolumn{5}{|c|}{ Table 14. Question 6 correlations } \\
\hline & & E6 & P6 & A6 \\
\hline E6 & Pearson Correlation & 1 & $.921^{* *}$ & $.720^{* *}$ \\
& Sig. (2-tailed) & .000 & .000 & .000 \\
& $\mathrm{~N}$ & 25 & 25 & 25 \\
\hline P6 & Pearson Correlation & $.921^{* *}$ & 1 & $.656^{* *}$ \\
& Sig. (2-tailed) & .000 & & .000 \\
& N & 25 & 25 & 25 \\
\hline A6 & Pearson Correlation & $.720^{* *}$ & $.656^{* *}$ & 1 \\
& Sig. (2-tailed) & .000 & .000 & \\
& N & 25 & 25 & 25 \\
\hline
\end{tabular}

**. Correlation is significant at the 0.01 level (2-tailed).

In relation to internal correlations among the three dimensions and as shown in table 14,

$$
\begin{array}{ll}
\text { - } & \mathrm{r}(\mathrm{E} 6, \mathrm{P} 6)=0.921 \\
\text { - } & \mathrm{r}(\mathrm{E} 6, \mathrm{~A} 6)=0.720 \\
\text { - } & \mathrm{r}(\mathrm{P} 6, \mathrm{~A} 6)=0.656
\end{array}
$$

\section{Discussion}

The purpose of this paper was to probe MA researchers' attitudes towards using the GO as a reading strategy for the sake of gathering information for their literature review. It aimed at valuing the experience of using the $\mathrm{GO}$ in relation to

- understanding main ideas of a text,

- understanding details of a text,

- understanding connections among ideas in a text,

- summarising ideas of a text,

- locating specific information and

- synthesising ideas from various sources. 
The graphic organiser as a reading strategy: A semantic differential measurement of MA researchers' attitudes

\subsection{Question1: Understanding main ideas of a text}

Considering the 0 score as the neutral point, it can be inferred from the results of the statistical treatment of the participants' ratings that the majority scored 1 and more in the three dimensions knowing that their median equals $[2,2.5]$. Thus, the results for this question were remarkably positive with a tendency towards higher values for evaluation and activity more than potency. In terms of consistency, evaluation and activity scored better than potency. Additionally, The Pearson Correlation Coefficients among the three dimensions showed positive relationships. Consequently and all in all, the results were in favour of positive attitudes towards the experience of using the $\mathrm{GO}$ as to understanding main ideas.

\subsection{Question2: Understanding details of a text}

Considering the 0 score as the neutral point, it can be deduced from the results of the statistical treatment of the participants' ratings that the majority scored 1 and more in the three dimensions knowing that their median equals 2. Thus, the results for this question were positive with a tendency towards the left (lower values) for evaluation, towards the right (higher values) for activity and symmetry for potency. In terms of consistency, evaluation and activity scored better than potency. Additionally, The Pearson Correlation Coefficients among the three dimensions showed positive relationships. Consequently and all in all, the results were in favour of positive attitudes towards the experience of using the GO as to understanding details of a text.

\subsection{Question3: Understanding connections among ideas in a text}

Considering the 0 score as the neutral point, it can be construed from the results of the statistical treatment of the participants' ratings that the majority scored 1 and more in the three dimensions knowing that their median equals $[1.5,2]$. Thus, the results for this question were positive with a tendency towards the left (lower 
values) for evaluation, towards the right (higher values) for activity and symmetry for potency. In terms of consistency, potency scored better than evaluation and activity. Additionally, The Pearson Correlation Coefficients among the three dimensions showed positive relationships. Consequently and all in all, the results were in favour of positive attitudes towards the experience of using the GO as to understanding connections among ideas in a text.

\subsection{Question4: Summarising ideas of a text}

Considering the 0 score as the neutral point, it can be understood from the results of the statistical treatment of the participants' ratings that the majority scored 1 and more in the three dimensions knowing that their median equals 2. Thus, the results for this question were positive with a tendency towards the left (lower values) for evaluation, towards the right (higher values) for potency and symmetry for activity. In terms of consistency, potency scored fairly more than evaluation and activity. Additionally, The Pearson Correlation Coefficients among the three dimensions showed positive relationships. Consequently and all in all, the results were in favour of positive attitudes towards the experience of using the GO as to understanding Summarising ideas of a text.

\subsection{Question5: Locating specific information}

Considering the 0 score as the neutral point, it can be understood from the results of the statistical treatment of the participants' ratings that the majority scored -0.5 and more in the three dimensions knowing that their median equals 2 . Thus, the results for this question were slightly positive with a tendency towards the left (lower values) for potency, and towards the right (higher values) for evaluation and activity. In terms of consistency, potency scored fairly more than evaluation and activity. Additionally, The Pearson Correlation Coefficients among the three dimensions showed positive relationships. Consequently and all in all, the results were in favour of positive attitudes towards the experience of using the GO as to summarising ideas of a text.

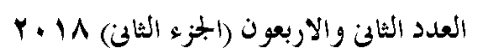

مجلة كلية التربية- جامعة عين شمس 
The graphic organiser as a reading strategy: A semantic differential measurement of MA researchers' attitudes

\subsection{Question6: Synthesising ideas from various sources}

Considering the 0 score as the neutral point, it can be realised from the results of the statistical treatment of the participants' ratings that the majority scored 1 and more in the three dimensions knowing that their median equals 2. Thus, the results for this question were neatly positive with a tendency towards the right (higher values) for activity and symmetry for evaluation and potency. In terms of consistency, activity scored fairly more than evaluation and potency. Additionally, The Pearson Correlation Coefficients among the three dimensions showed positive relationships. Consequently and all in all, the results were in favour of positive attitudes towards the experience of using the $\mathrm{GO}$ as to synthesising ideas from various sources. 


\section{Dr. Samia Kara}

\section{Conclusion}

The starting point of this paper was a question raised in relation to the $\mathrm{GO}$ as a reading strategy used in the literature review and attitudes of MA researchers who are undertaking their research in relation to English or via English towards it as an experience. The latter subsumed the elements of

- understanding main ideas of a text,

- understanding details of a text,

- understanding connections among ideas in a text,

- summarising ideas of a text,

- locating specific information and

- synthesising ideas from various sources.

The results emanating from the use of the SD with its three dimensions have demonstrated that the participants do have positive attitudes towards the $\mathrm{GO}$ in relation to the aforementioned functions.

Because it was meant to be exploratory, this study cannot be generalised especially because of the convenience nature of the sample. However, there is some faith that it might open more doors for research along the same lines and with more sophisticated tools. In fact, a clearer understanding of the mechanisms of the GO might help its candidature as an official component in any curriculum in connection with the reading skill for literature review. 
The graphic organiser as a reading strategy: A semantic differential measurement of MA researchers' attitudes

\section{References}

Alexander, A.A.; Schallert, DL. \& Hare, C.H. 1991. Coming to terms: How researchers in learning and literacy talk about knowledge. Review of Educational Research, 61, 315-343.

Allport, G.W. 1935. Attitudes. In Murchison, C. (Ed.). Handbook of Social Psychology, Clark University. Press, Worcester, Mass., 798-844.

Ausubel, D. 1968. Educational psychology: A cognitive view. New York: Holt, Rinehart \& Winston.

Barton- Arwood, S. M. \& Little, M. A. (2013). Using graphic organisers to access the general curriculum at the secondary level. Intervention in School and Clinic 49(1), 6-13.

Bohner G, Wänke, M. 2002. Attitudes and attitude change. Social Psychology. Hove, UK: Psychology Press.

Clark, J. M. \& Paivio, A. 1991. Dual coding theory and education. Educational Review, 3(3), 149-210.

Dicecco, V. \& Gleason, M.M. (2002). Using graphic organisers to attain relational knowledge from expository text. Journal of Learning Disabilities, 35(4), 306-320.

Doyle, J.R. \& Bottomley, P.A. 2010. Norms for Osgood's affective meaning (evaluation, potency, activity): Ratings of logos, colours, products and services, names and typefaces. Retrieved on Jan $2^{\text {nd }}, 2016$ from http://ssrn.com/abstract=1640198.

Eagly, A.H., Chaiken, S. 1993. The psychology of attitudes. Harcourt Brace Jovanivich College Publishers.

Education Bureau of Hong Kong (2016). The use of graphic organisers to enhance thinking skills in the learning of economics. Retrieved on 0829/2017 from http://www.edb.gov.hk/attachment/en/curriculumdevelopment $/ \mathrm{kla} / \mathrm{pshe} /$ references-andresources/economics/use_of_graphic_organisers.pdf

Fishbein, M. \& Ajzen, I. 1975. Belief, attitude, intention and behaviour: An introduction to theory and research. Reading, MA: Addison-Wesley. Gawronski, B. \& Bodenhausen, G.V. 2006. Associative and propositional processes in evaluation: An integrative review of implicit and explicit attitude change. Psychological Bulletin, 132(5), 692-731. 


\section{Dr. Samia Kara}

Gieselman, S. (2008). Graphic organisers in the social studies classroom: Effective content integration tools for pre-service teachers. Kentucky Journal of Excellence in College Teaching and Learning,6,Art.2.

Horton, S.V., Lovitt, T.C., Bergerud, D. (1990). The effectiveness of graphic organisers for three classifications of secondary students in content area classes. Journal of Learning Disabilities, 23(1), 12-22.

Darch, C., \& Eaves, R. C. (1986). Visual displays to increase comprehension of high school learning-disabled students. The Journal of Special Education, 20(3), 309-318.

Heise, D.R. 1970. The semantic differential and attitude. In Summers, G.F. Attitude Measurement, 235-253.

Kim, A., Vaughn, S, Wanzek, J. \& Wei, S. (2004). Graphic organisers and their effects on the reading comprehension of students with LD: A synthesis of research. Journal of Learning Disabilities, 37(2), 105-118.

Kools, M., Van De Wiel, M.W.J., Ruiter, R. A. C. Cruts, A. \& Kok, G. (2006). The effect of graphic organisers on subjective and objective comprehension of a health education text. Health Education \& Behaviour, 33 (6), 760-772.

Lavrakas, PJ (2008). Convenience Sampling. Encyclopaedia of Survey Research Method. DOI: Http://dx.doi.org/10.4135/9781412963947.n105. Retrieved on Dec.24 $4^{\text {th }}$, 2017 from: http://methods.sagepup.com/reference/encyclopedia-of-survey-researchmethds/n105.xml

Manoli, P., \& Papadoupolou, M. (2012). Graphic organisers as a reading strategy: Research findings and issues. Creative Education, 3(3), 348356.

Marzano, R.J., Gaddy, B.B., \& Dean, C. (2000). What works in classroom instruction. McRel.

Marzano, R.J., Pickering, D.J., \& Pollock, J.E. (2001). Classroom instruction that works: Research -based strategies for increasing student achievement. McRel.

Nunnally, J.C. \& Bernstein, I. H. 1994. Psychometric theory. NY: McGraw-Hill.

Oskamp, S., Schultz, P. W. 2005. Attitudes and opinions. Lawrence Erlbaum Associates, Inc.

Osgood, C.E., Suci, G.J. and Tannenbaum, P.H. 1957. The measurement of meaning. University of Illinois Press.

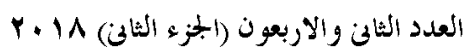

مجلة كلية التربية- جامعة عين تمس م 
The graphic organiser as a reading strategy: A semantic differential measurement of MA researchers' attitudes

Paivio, A. 1969. Mental imagery, associative learning and imagery. Psychological review, 76, 241-263.

Torres, D. B. (2015). Effectiveness of the use of graphic organisers and summaries: A case study of adult EFL students in a reading comprehension course. Revista De Lenguas Modernas, 22, 267-295.

Triandis, H.C. 1975. Culture training, cognitive complexity, and interpersonal attitudes . In Brislin, R. Bochner, S., and Lonner, W. (Eds.) Cross-cultural Perspectives on Learning. New York : Halsted/Wiley/ Sage, 39-77. 